\title{
Neural Cell Adhesion Molecule L1-Transfected Embryonic Stem Cells Promote Functional Recovery after Excitotoxic Lesion of the Mouse Striatum
}

\author{
Christian Bernreuther, ${ }^{1,2 *}$ Marcel Dihné, ${ }^{1 *}$ Verena Johann, ${ }^{3}$ Johannes Schiefer, ${ }^{3}$ Yifang Cui, ${ }^{1}$ Gunnar Hargus, ${ }^{1}$ \\ Janinne Sylvie Schmid, ${ }^{1}$ Jinchong Xu, ${ }^{1,4}$ Christoph M. Kosinski, ${ }^{3}$ and Melitta Schachner ${ }^{1}$ \\ ${ }^{1}$ Zentrum für Molekulare Neurobiologie Hamburg, University of Hamburg, D-20251 Hamburg, Germany, ${ }^{2}$ Institute for Neuropathology, University Medical \\ Center Hamburg-Eppendorf, D-20246 Hamburg, Germany, ${ }^{3}$ Neurology Center, University Medical Center Rheinisch-Westfälische Technische Hochschule- \\ Aachen, D-52074 Aachen, Germany, and ${ }^{4}$ Sino-German Center for Neuroscience, Dalian University Medical School, Dalian, Liaoning 116027, China
}

We have generated a murine embryonic stem cell line constitutively expressing L1 at all stages of neural differentiation to investigate the effects of L1 overexpression on stem cell proliferation, migration, differentiation, cell death, and ability to influence drug-induced rotation behavior in an animal model of Huntington's disease. L1-transfected cells showed decreased cell proliferation in vitro, enhanced neuronal differentiation in vitro and in vivo, and decreased astrocytic differentiation in vivo without influencing cell death compared with nontransfected cells. L1 overexpression also resulted in an increased yield of GABAergic neurons and enhanced migration of embryonic stem cell-derived neural precursor cells into the lesioned striatum. Mice grafted with L1-transfected cells showed recovery in rotation behavior 1 and 4 weeks, but not 8 weeks, after transplantation compared with mice that had received nontransfected cells, thus demonstrating for the first time that a recognition molecule is capable of improving functional recovery during the initial phase in a syngeneic transplantation paradigm.

Key words: neural cell adhesion molecule L1; embryonic stem cell; neuronal differentiation; quinolinic acid; striatum; functional recovery

\section{Introduction}

Regeneration of functional activity after loss of GABAergic projection neurons in the striatum as seen in Huntington's disease is an important goal in restorative medicine. Recognition molecules at the cell surface and in the extracellular matrix have a potential to favor processes that regulate survival, neurite outgrowth, and synapse formation not only during development but also in the adult after trauma. Among the recognition molecules that mediate these functions is L1, a homophilically and heterophilically binding member of the Ig superfamily that is expressed by neurons but not by astrocytes and oligodendrocytes in the CNS and by neurons and Schwann cells in the peripheral nervous system (Lindner et al., 1983; Rathjen and Schachner, 1984; Moos et al., 1988; Appel et al., 1993; Kamiguchi and Yoshihara, 2001). L1 promotes neuronal survival, neurite outgrowth (Lemmon et

Received June 10, 2005; revised Sept. 11, 2006; accepted Sept. 11, 2006.

This work was supported by German Research Foundation Grants Di 881/1-1 and Scha 185/36, by a START grant from the Medical Faculty of the Technical University of Aachen (C.M.K.), and by a donation from Erika and Conrad W. Schnyder (M.S.). We thank Alexander Nikonenko and Andrey Irintchev for help with statistics and migration studies and Masaru Okabe for providing the EGFP transgenic mice. We declare that we have no competing financia interests.

${ }^{*}$ C.B. and M.D. contributed equally to this work.

Correspondence should be addressed to Dr. Melitta Schachner, Zentrum für Molekulare Neurobiologie Hamburg, Falkenried 94, D-20251 Hamburg, Germany. E-mail: melitta.schachner@zmnh.uni-hamburg.de.

M. Dihné's present address: Universitätsklinikum Düsseldorf, Neurologische Klinik, Moorenstrasse 5, D-40225 Düsseldorf, Germany.

D01:10.1523/JNEUROSCI.2688-06.2006

Copyright $\odot 2006$ Society for Neuroscience $\quad$ 0270-6474/06/2611532-08\$15.00/0 al., 1989; Appel et al., 1993; Chen et al., 1999; Kleene et al., 2001; Dong et al., 2003), and synaptic plasticity, as shown by modification of synaptic efficacy both in vitro and in vivo as well as in learning and memory as seen in L1-deficient mice and humans (Luthi et al., 1996; Fransen et al., 1998a,b; Tiunova et al., 1998; Wolfer et al., 1998; Demyanenko et al., 1999; Pradel et al., 2000; Law et al., 2003; Saghatelyan et al., 2004; Venero et al., 2004). Furthermore, L1 is involved in myelination in the central and peripheral nervous systems (Seilheimer et al., 1989; Wood et al., 1990; Haney et al., 1999; Barbin et al., 2004). We have shown previously that L1 influences differentiation of neural stem cells into neurons in vitro (Dihné et al., 2003). Furthermore, L1 has been shown to promote functional recovery in adult rats after contusion-induced spinal cord injury (Roonprapunt et al., 2003) and optic nerve lesion (Xu et al., 2004) and is involved in regenerative growth of Purkinje cell axons in vivo (Zhang et al., 2005), thus overcoming regeneration-adversive cues that prevail in the CNS of adult mammals.

Based on these findings, we investigated whether embryonic stem (ES) cells transfected to overexpress L1 at the cell surface would show beneficial effects after syngeneic transplantation into adult mice with quinolinic acid-induced striatal lesion. We show that L1-transfected and predifferentiated ES cells indeed allow for better differentiation into neurons, migration, and functional recovery of rotation behavior in mice after depletion of striatal GABAergic projection neurons that are crucial for coordinated motor activity. 


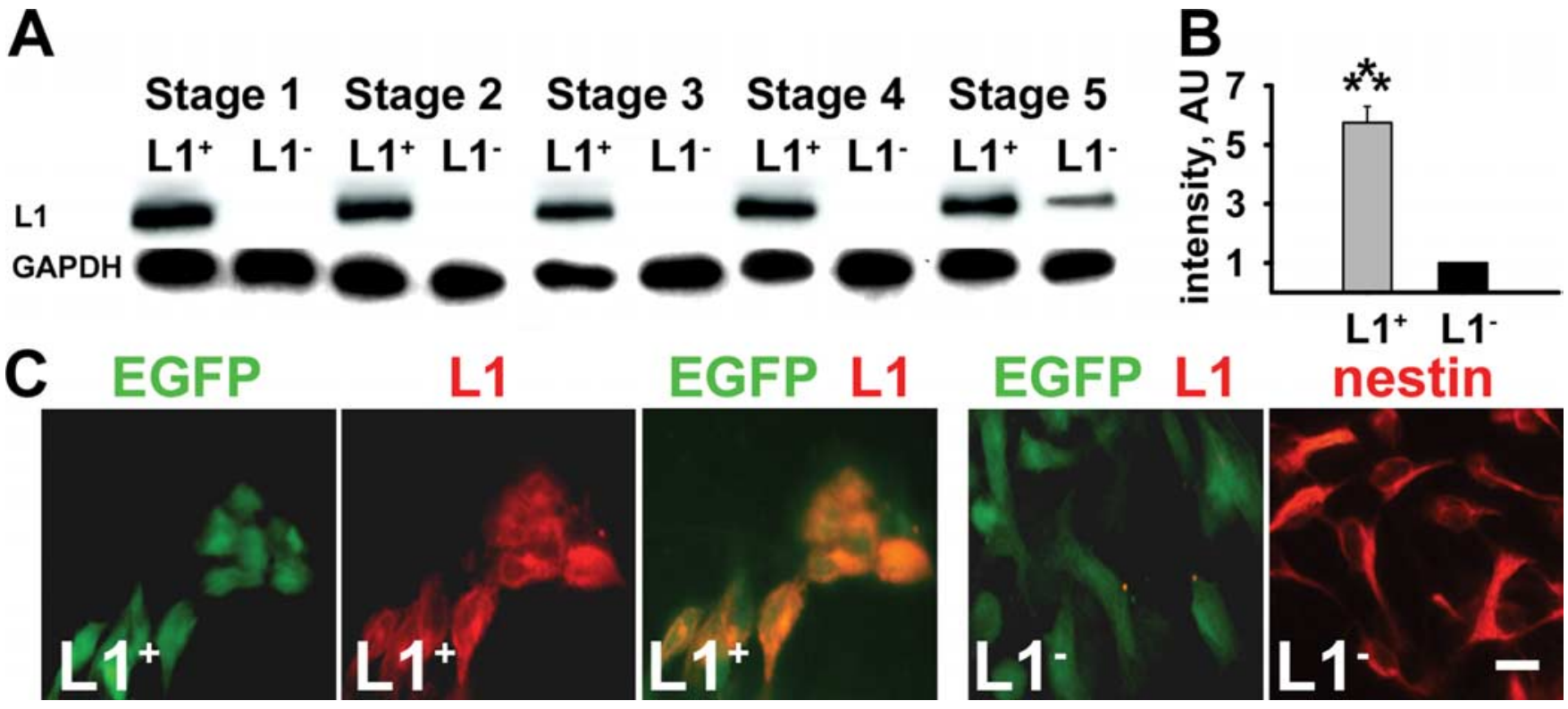

Figure 1. Transfected ES cells express $\mathrm{L} 1$ at all stages of differentiation. $A$, Immunoblot analysis of $\mathrm{L} 1$ expression in transfected $\left(\mathrm{L}^{+}{ }^{+}\right)$and mock-transfected $\left(\mathrm{L} 1^{-}\right) \mathrm{GFP}{ }^{+} \mathrm{ES}$ cells differentiated by the five-stage differentiation protocol at day 2 of stages 1 and 2, day 6 of stages 3 and 4, and day 7 of stage 5 . Note that transgenic L1 is expressed throughout all stages of differentiation. Immunoblot analysis of glyceraldehyde 3-phosphate dehydrogenase (GAPDH) is shown as a loading control. $\boldsymbol{B}$, Quantification of the intensity in the immunoblot analysis of L1 expression in stage 5. Arbitrary units (AU) normalized for L1 expression in L1 ${ }^{-}$cells are shown (mean \pm SEM). Student's $t$ test was performed for statistical analysis $\left({ }^{* * *} p<0.001\right)$. C, L1 overexpression at the cell surface was evaluated using anti-L1 (red) immunostaining and fluorescence light microscopy of live L1 ${ }^{-}$and L1 ${ }^{+}$cells at stage 4. Note the expression of GFP (green) in L1 ${ }^{-}$and L1 ${ }^{+}$cells. Neural differentiation of ES cells was confirmed by immunostaining of cells differentiated to stage 4 for nestin (red). Scale bar, $10 \mu \mathrm{m}$. EGFP, Enhanced GFP.

\section{Materials and Methods}

Generation of $\mathrm{L1}^{+}$ES cells. Standard molecular biology protocols were used for the generation of pPGK-L1-neo, a modified pKO-V924 plasmid (Stratagene, La Jolla, CA) containing full-length murine L1-cDNA (Moos et al., 1988) under the influence of the promoter of the murine 3-phoshoglycerokinase amplified from pKOSelectneo (Stratagene) and for neomycin phosphotransferase. ES cells expressing enhanced green fluorescent protein (GFP) under the influence of the $\beta$-actin promoter $\left(\mathrm{GFP}^{+}\right.$ES cells) (Chen et al., 2005) were transfected with pPGK-L1-neo by electroporation $(0.25 \mathrm{kV}, 500 \mu \mathrm{F})$, and transfected clones were selected for by growth in the presence of G418 $(250 \mu \mathrm{g} / \mathrm{ml})$. The selected clones were screened for expression of L1 by immunoblot analysis. Two clones showing strongest expression of $\mathrm{L} 1\left(\mathrm{~L} 1{ }^{+}\right.$cells) as determined by Western blot analysis and immunocytochemistry of live cells through stages $1-5$ according to Lee et al. (2000) were used for additional experiments. GFP ${ }^{+}$ES cells transfected with the neomycin resistance only containing plasmid pKOSelectneo were used as controls ( $\mathrm{L1}^{-}$cells).

Maintenance of undifferentiated ES cells (stage 1), embryoid body formation (stage 2), selection of nestin-positive cells (stage 3), and expansion of nestin ${ }^{+}$neural precursor cells (stage 4) was performed as described previously (Okabe et al., 1996; Lee et al., 2000) with modifications. The medium applied to the cells in stage 4 differs from the medium mN3FL described by Lee et al. (2000) by the omittance of PDGF and laminin and the replacement of insulin, transferrin, selenium, progesterone, hydrocortisone, and putrescine by B-27 supplement. Differentiation was induced by omittance of basic FGF (bFGF) (stage 5).

Immunoblot analysis. For determination of $\mathrm{L} 1$ expression at various stages of differentiation in vitro, immunoblotting was performed as described previously (Dihné et al., 2003) using monoclonal rat L1 antibody (1:1000 diluted) (Appel et al., 1993). Mouse monoclonal antibodies against glyceraldehyde 3-phosphate dehydrogenase (1:3000; Chemicon, Temecula, CA) were used to control for protein loading.

Immunocytochemistry and immunohistochemistry. Cultured cells were fixed in $4 \%$ paraformaldehyde in PBS, $\mathrm{pH} 7.3$, washed with PBS, and incubated in $0.1 \%$ bovine serum albumin (Sigma, St. Louis, MO) for 40 min. For labeling with bromodeoxyuridine (BrdU) in vitro, BrdU (Sigma) was added to the culture medium to a final concentration of 10 mM $8 \mathrm{~h}$ before fixation. For immunohistochemistry, mice were perfused with $4 \%$ paraformaldehyde in PBS. Perfused brain tissue was soaked in $20 \%$ sucrose overnight, frozen in liquid nitrogen-cooled 2-methylbutane, and cut on a cryostat at $25 \mu \mathrm{m}$. Primary antibodies, used at $4^{\circ} \mathrm{C}$ overnight, were monoclonal mouse antibodies to $\beta$-tubulinIII (1:400; Sigma), nestin (1:50; Developmental Studies Hybridoma Bank, Iowa City, IA), CNPase (1:1000; Sigma), NeuN (1:1000; Chemicon), and BrdU (1:50; Chemicon); a monoclonal rat antibody to myelin basic protein (MBP) (1:200; Chemicon); polyclonal rabbit antibodies to caspase-3 (1: 2000; R \& D Systems, Minneapolis, MN), dopamine- and cAMPregulated phosphoprotein-32 (DARPP-32) (1:500; Chemicon), glial fibrillary acidic protein (1:1000; Dako, Carpinteria, CA), Ki-67 (1:50; Abcam, Cambridge, UK), L1 (1:250) (Rathjen and Schachner, 1984), glutamate decarboxylase (GAD) (GAD-65/67, 1:500; Sigma), neurofilament (NF)-200 (1:200; Sigma), and tyrosine hydroxylase (TH) (1:100; Chemicon); and a polyclonal goat antibody to doublecortin (DCX) (Santa Cruz Biotechnology, Santa Cruz, CA). For staining with BrdU antibody, sections were first incubated in $50 \%$ formamide/SSC at $65^{\circ} \mathrm{C}$ for $2 \mathrm{~h}$, followed by incubation in $2 \mathrm{~N} \mathrm{HCl}$ at $37^{\circ} \mathrm{C}$ for $30 \mathrm{~min}$, before using primary antibody at $4^{\circ} \mathrm{C}$ overnight. For detection of first antibodies, appropriate secondary antibodies, coupled to Cy2 or Cy3 (all from Dianova, Hamburg, Germany), were used. Some coverslips and sections were counterstained for $10 \mathrm{~min}$ with $50 \mu \mathrm{g} / \mathrm{ml} \mathrm{4}$,'6-diamidino-2phenylindole (DAPI; Sigma) for staining of cell nuclei. For immunostaining of live cells, fixation was omitted, and cells were washed and incubated with primary antibody on ice for $15 \mathrm{~min}$, followed by washing and incubation with secondary antibody for $15 \mathrm{~min}$ on ice. Subsequently, cells were fixed in $4 \%$ paraformaldehyde in PBS. Specimens were examined with a fluorescence (Axioplan 2; Carl Zeiss Microimaging, Thornwood, NY) or confocal laser-scanning (LSM510; Carl Zeiss Microimaging) microscope.

Quantitative real-time PCR. Total RNA was extracted from 2-mmthick sections containing mainly the graft but also the surrounding host striatum of brains grafted with $\mathrm{L}^{+}{ }^{+}$or $\mathrm{L}^{-}{ }^{-}$cells using the lipid tissue RNA extraction kit (Qiagen, Hilden, Germany) according to the manufacturer's instructions. For reverse transcription, the SuperScript First Strand Synthesis System (Invitrogen, Karlsruhe, Germany) was used to synthesize cDNA in a $20 \mu \mathrm{l}$ reaction volume containing $1 \mu \mathrm{g}$ of DNase I-treated RNA and $100 \mathrm{ng}$ of random hexamer primers according to the 


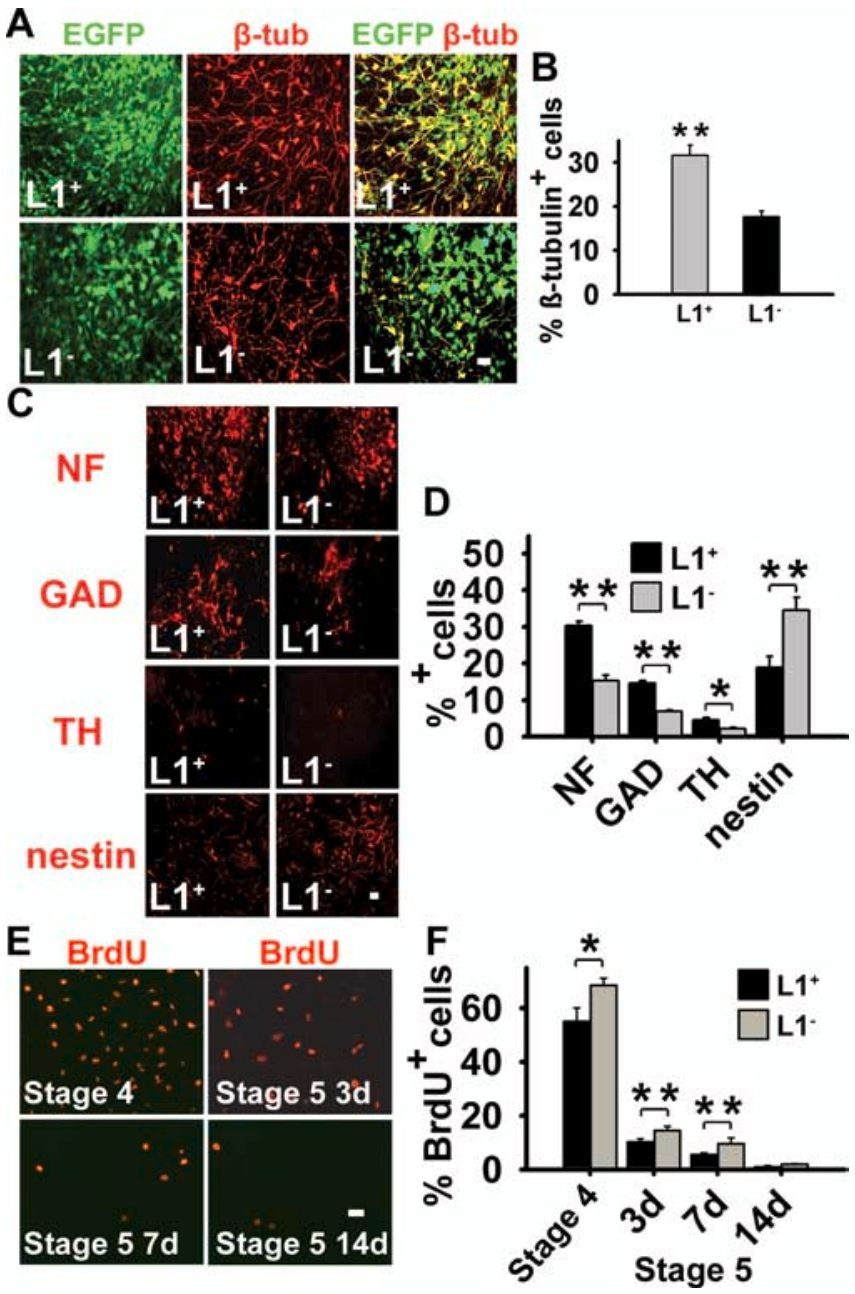

Figure 2. L1 expression increases neuronal differentiation and decreases proliferation in vitro. A, Generation of neurons from $\mathrm{L}_{1}{ }^{-}$and $\mathrm{L} 1^{+}$ES cells was determined at day 7 of stage 5 by immunostaining for $\beta$-tubulinllI ( $\beta$-tub; red). GFP ${ }^{+}$cells, green; $\beta$-tubulinllI/GFP ${ }^{+}$cells, yellow. The proportion of $\beta$-tubulinlll ${ }^{+}$cells of all GFP ${ }^{+}$cells was greater in $\mathrm{L}^{+}{ }^{+}$cells than in $\mathrm{L} 1^{-}$cells. Scale bar, $20 \mu \mathrm{m}$. EGFP, Enhanced GFP. B, Percentages of $\beta$-tubulinlll ${ }^{+}$cells of all $\mathrm{GFP}^{+}$cells are shown at day 7 of stage 5 (mean \pm SEM). Student's $t$ test was performed for statistical analysis ( $\left.{ }^{* *} p<0.01\right)$. C, At day 14 of stage 5, mature neuronal proteins NF-200 (NF), $G A D$, and TH and the neural stem cell protein nestin (all in red) were determined by immunocytochemistry in $\mathrm{L1}^{-}$and $\mathrm{L1}^{+}$cells. The proportion of $\mathrm{NF}^{+}, \mathrm{GAD}^{+}$, and $\mathrm{TH}^{+}$cells was greater in the $\mathrm{L}^{+}$than in the $\mathrm{L}^{-}{ }^{-}$cells, whereas the proportion of nestin ${ }^{+}$cells was higher in $\mathrm{L}^{-}{ }^{-}$cells. Scale bar, $10 \mu \mathrm{m}$. D, Percentages of $\mathrm{NF}^{+}, \mathrm{GAD}^{+}, \mathrm{TH}^{+}$, and nestin ${ }^{+}$cells at day 14 of stage 5 (mean \pm SEM). ${ }^{*} p<0.05$, ${ }^{* *} p<0.01$ (Student's $t$ test). $\boldsymbol{E}$, BrdU incorporation was determined at day 7 of stage 4 and at days 3,7 , and 14 of stage 5 by immunostaining for BrdU (red) after a pulse labeling of $8 \mathrm{~h}$ with $10 \mathrm{~mm}$ BrdU. Scale bar, $10 \mu \mathrm{m}$. F, Percentages of $\mathrm{BrdU}^{+}$cells of all cells are shown at day 7 of stage 4 and days 3,7 , and 14 of stage 5 (mean \pm SEM). Student's t test was performed for statistical analysis $\left({ }^{*} p<0.05 ;{ }^{* *} p<0.01\right) .3 d$, Day 3 ; 7d, day $7 ; 14 d$, day 14 .

manufacturer's instructions. The cDNA product was treated with $2 \mathrm{U}$ of RNase $\mathrm{H}$ (Invitrogen) for $20 \mathrm{~min}$ at $37^{\circ} \mathrm{C}$, followed by heat inactivation of the enzyme at $70^{\circ} \mathrm{C}$ for $15 \mathrm{~min}$. An identical reaction without the reverse transcriptase was performed to verify the absence of genomic DNA. The cDNA was diluted 1:4 in sterile water and stored at $-20^{\circ} \mathrm{C}$ until use. Quantitative real-time PCR was performed using the qPCR Core kit for SYBR Green I (Eurogentec, Seraing, Belgium) following the manufacturer's instructions. Each reaction $(20 \mu \mathrm{l})$ contained $1 \mu \mathrm{l}$ of cDNA, $3.5 \mathrm{~mm}$ $\mathrm{MgCl}_{2}, 200 \mu \mathrm{M}$ dNTPs, $0.5 \mu \mathrm{M}$ of each primer, and $0.025 \mathrm{U} / \mu \mathrm{l}$ Hot GoldStar enzyme in the reaction buffer in addition to SYBR Green I. Primers used were $5^{\prime}$-TTGAGCACGTCATCGAAGAGC-3' and $5^{\prime}$ CCAAAGGCACTTGACTGCTGA-3' for the detection of brain-derived neurotrophic factor (BDNF), 5' -TATTGCAGCGGTTCCTGTGAA-3' and $5^{\prime}$-CATGCCTGGCCTACTTTGTCA- $3^{\prime}$ for glial cell line-derived neurotrophic factor (GDNF), 5'-GCCCATGGTACAATCCCTTTC-3'

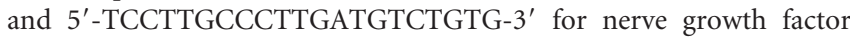
(NGF), 5'-TCACCACGGAGGAAACGCTAT- ${ }^{\prime}$ and $5^{\prime}$-TCAATGGCTGAGGACTTGTCG-3' for neurotrophin-3 (NT-3), and $5^{\prime}$-GTTCTTTGCTGACCTGCTGGA- $3^{\prime}$ and 5'-TCCCCCGTTGACTGATCATT-3' for hypoxanthin phosphoribosyl transferase (hprt). Specificity was validated by sequencing the amplified products. Duplicate reactions were prepared for each sample along with a no-template and a no-reverse transcription negative control. PCR conditions consisted of one cycle at $50^{\circ} \mathrm{C}$ with a $2 \mathrm{~min}$ hold, followed by $95^{\circ} \mathrm{C}$ with a $10 \mathrm{~min}$ hold and 45 two-segment cycles $\left(95^{\circ} \mathrm{C}\right.$ with a $15 \mathrm{~s}$ hold and $60^{\circ} \mathrm{C}$ with a $1 \mathrm{~min}$ hold) using the Applied Biosystems (Foster City, CA) PRISM 7900 HT sequence detection system. Threshold cycles $\left(\mathrm{c}_{\mathrm{T}}\right)$ were determined with SDS 2.0 software (Applied Biosystems) for each sample and normalized using the $c_{\mathrm{T}}$ for hprt as a reference for overall expression levels.

Transplantation. Three days before transplantation, the right striatum of 3-month-old C57BL/6J mice was lesioned by stereotaxic injection of 1 $\mu \mathrm{l}$ of $60 \mathrm{nmol}$ of quinolinic acid (Sigma) at the following coordinates in relation to bregma: $0.4 \mathrm{~mm}$ anteroposterior, $1.8 \mathrm{~mm}$ mediolateral, and $3.0 \mathrm{~mm}$ dorsal. On the day of transplantation, ES cells differentiated to day 3 of stage 5 were dissociated by $0.05 \%$ trypsin $/ 0.04 \%$ EDTA and resuspended in HBSS without $\mathrm{Ca}^{2+}$ and $\mathrm{Mg}^{2+}$ (HBSS-) at a density of 100,000 viable cells per microliter. One microliter of stage 5 precursor cell suspension was grafted into the lesioned striatum using the same coordinates as for the lesion. The number of animals studied was as follows: $\mathrm{L} 1^{+}$cells $(n=24), \mathrm{L} 1^{-}$cells $(n=24)$, and sham-injected (HBSS - only) controls $(n=19)$. For analysis of incorporation of BrdU, mice were given intraperitoneal injections of $100 \mathrm{mg}$ of BrdU (Sigma) on days 3-7 after grafting. Grafts were analyzed 1, 4, and 8 weeks after transplantation. All animal experiments were approved by the University and State of Hamburg Animal Care Committees.

Determination of differentiation and proliferation. To determine total cell numbers in vitro, cells were counterstained with DAPI, and the ratio of cell type-specific, marker-positive or $\mathrm{BrdU}^{+}$cells of all $\mathrm{DAPI}^{+}$cells was calculated. To determine total numbers of donor cells in vivo, $\mathrm{GFP}^{+}$ cells were counted, and the ratio of cell type-specific, marker-positive cells of all $\mathrm{GFP}^{+}$cells was calculated. At least three independent experiments in duplicates and at least 1000 cells per marker and experiment were analyzed. Percentages of double-labeled cells were determined, and mean values \pm SEM were calculated.

Graft volume and density. Unbiased estimates of the total number of grafted cells and graft volume per animal, 1, 4, and 8 weeks after transplantation, were calculated according to the optical dissector and Cavalieri methods (Howard and Reed, 1998). An Axioskop microscope (Carl Zeiss Microimaging) and a Neurolucida software-controlled computer system were used for quantitative analysis (MicroBrightField Europe, Magdeburg, Germany). Graft volume and cell density of the graft were determined measuring every 10th section of the graft. Transplanted cells were identified by their GFP signal. Graft areas were outlined on digitized images to calculate volumes considering section thickness and frequency. Using random sampling in the graft core and in the periphery of the graft, cell counts were performed according to the optical dissector principle at a magnification of $40 \times$.

Cell migration. The graft edge was delineated at low magnification in digitized images. The shortest distances of at least 400 individual cells from the graft edge of recipient animals were determined ( $n=6$ for $\mathrm{L}^{+}$ grafts, $n=6$ for $\mathrm{L}^{-}$grafts) at higher magnification $(40 \times)$.

Behavioral analysis. Thirty adult C57BL/6J mice were used for the behavioral analyses. All mice received a unilateral striatal lesion through injection of $60 \mathrm{nmol}$ of quinolinic acid. Mice were then randomly assigned to three groups: one for the transplantation of $\mathrm{L}^{-}$cells $(n=11)$, one for the transplantation of $\mathrm{L}^{+}$cells $(n=9)$, and one that received only vehicle (HBSS - ) injection (sham-injected group, $n=10$ ). Druginduced rotation behavior was tested 1,4 , and 8 weeks after quinolinic acid lesion and cell transplantation. All behavioral tests were performed at the beginning of the animals' dark phase. Rotation was measured in a bank of automated rotometer bowls (Accuscan Instruments, Columbus, 


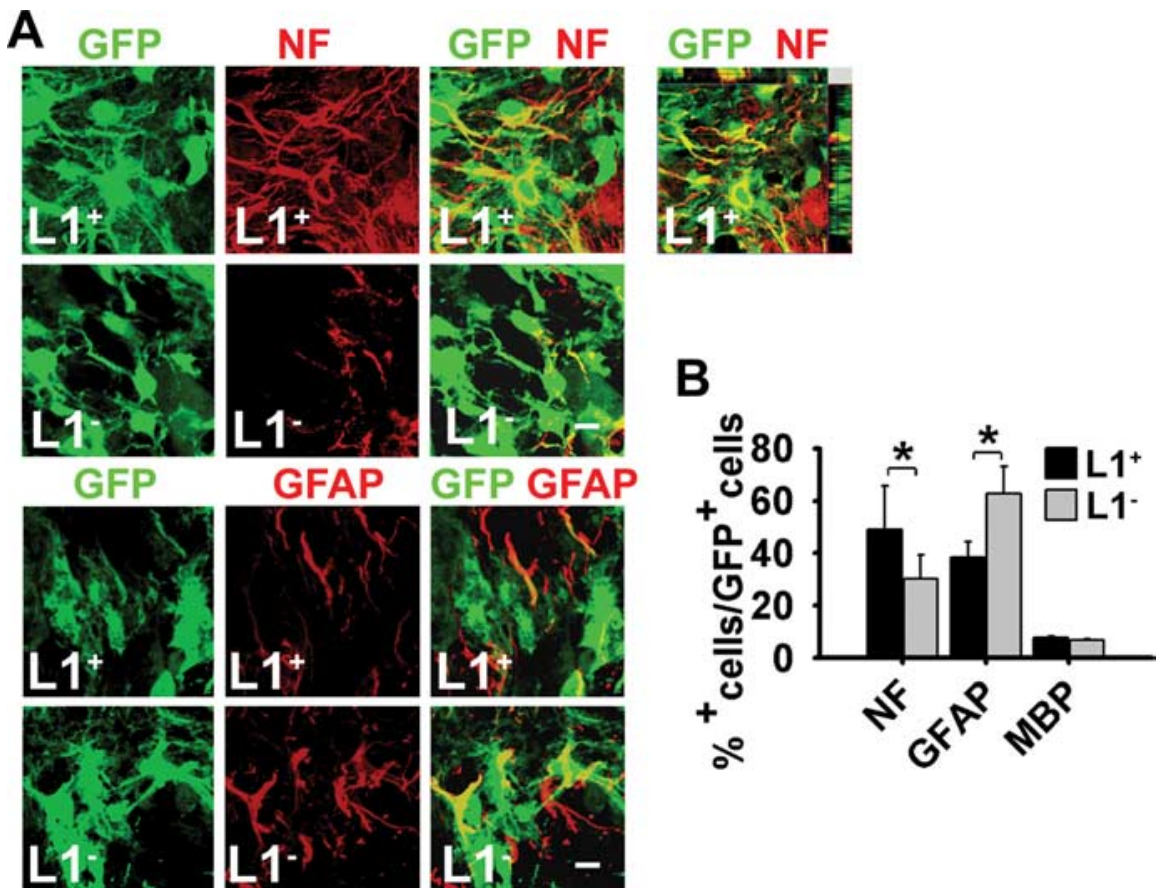

Figure 3. $\mathrm{L} 1^{+}$cells grafted into the quinolinic acid-lesioned striatum show increased neuronal differentiation. $\boldsymbol{A}$, Laserscanning microscopy illustrating immunohistochemical analysis of grafts of early stage 5 cells derived from L1 ${ }^{-}$and L1 ${ }^{+}$ES cells with the neuronal marker NF and the astrocytic marker GFAP (all in red) 4 weeks after transplantation of GFP ${ }^{+}$(green) cells. Donor-derived marker ${ }^{+}$cells in merged images appear yellow. NF staining of an L1 ${ }^{+}$graft with Z-series is displayed at top right. Note the increased expression of NF and the decreased expression of GFAP in $\mathrm{L}^{+}{ }^{+}$grafts compared with L1 ${ }^{-}$grafts. Scale bar, 10 $\mu \mathrm{m} . \boldsymbol{B}$, Percentages of cell type-specific marker ${ }^{+}$cells in $\mathrm{L}^{+}(n=6)$ or $\mathrm{L1}^{-}(n=6)$ grafts 4 weeks after transplantation (mean \pm SEM). ${ }^{*} p<0.05$ (Student's $t$ test).

$\mathrm{OH})$. Mice were tested for rotation in response to an intraperitoneal injection of $5 \mathrm{mg} / \mathrm{kg} \mathrm{D}$-amphetamine sulfate in sterile water. Tests were conducted over $30 \mathrm{~min}$ (Fricker et al., 1996). Net right turns were calculated as the number of $360^{\circ}$ right turns minus the number of left turns. After behavioral testing, mice were killed, and lesion sizes were determined in sections stained immunohistochemically for DARPP-32. Mice with a lesion size of $<50 \%$ of the volume of the striatum were excluded from the behavioral analysis. Lesion size was not significantly different between the experimental groups.

Statistical evaluation. All experiments were performed in a doubleblinded manner, and Student's $t$ test was used for statistical evaluation if not indicated otherwise.

\section{Results}

Generation of ES cells expressing $L 1$ at all stages of differentiation

We used a 3-phosphoglycerokinase promoter-containing plasmid driving the expression of a murine full-length L1-cDNA in ES cell lines constitutively expressing GFP to establish stably L1expressing ES cell lines ( $\mathrm{L}^{+}$cells) that are $\mathrm{GFP}^{+}$at all stages of differentiation. $\mathrm{GFP}^{+}$ES cells were subjected to the five-stage differentiation protocol (Okabe et al., 1996; Lee et al., 2000). Mock-transfected ES cell lines (L1 ${ }^{-}$cells) did not express significant levels of $\mathrm{L} 1$ at stages $1-4$ as determined by immunoblotting. With terminal neuronal differentiation in stage 5, L1 expression was detected as a result of endogenous expression of basal levels of $\mathrm{L} 1$ by newly generated neurons (Fig. $1 A$ ). In contrast, $\mathrm{L} 1{ }^{+}$cells stably expressed L1 at stages $1-5$ (Fig. $1 A$ ). Quantification of L1 expression at stage 5 by immunoblot analysis showed a fivefold higher level of L1 expression in $\mathrm{L}^{+}$cells compared with $\mathrm{L}^{-}$ cells (Fig. $1 B$ ). At stage 4 , almost all cells that were $\mathrm{L}^{+}{ }^{+}$or $\mathrm{L1}^{-}$at the cell surface expressed nestin, a marker for immature neural cells (Fig. 1C). Thus, we generated a highly enriched population of $\mathrm{GFP}^{+}$and nestin ${ }^{+}$neural precursor cells expressing increased levels of $\mathrm{L} 1$ at all stages of differentiation.

\section{$\mathrm{L}^{+}$cells show increased neuronal differentiation and decreased proliferation in vitro}

To determine the effects of $\mathrm{L} 1$ overexpression on neural differentiation in vitro, stage 4 cells were induced to differentiate by removal of bFGF. At day 7 of stage 5 , $\beta$-tubulinIII ${ }^{+}$neurons were twice as abundant in the $\mathrm{L}^{+}$group versus the L1 ${ }^{-}$group (Fig. $2 A, B$ ), with no significant differences in the percentages of astrocytes and oligodendrocytes between the two groups (data not shown). At day 14 of stage 5, neurons expressing NF200, the GABAergic marker GAD, and the dopaminergic marker TH (Fig. 2C) were increased twofold in the $\mathrm{L}^{+}$group versus the $\mathrm{L1}^{-}$group (Fig. $2 \mathrm{D}$ ), with a corresponding decrease in nestin ${ }^{+}$cells (Fig. 2C,D). Furthermore, $\mathrm{L1}^{+}$cells showed decreased proliferation as determined by incorporation of $\mathrm{BrdU}$ at day 7 of stage 4 and at days 3 and 7 of stage 5 compared with $\mathrm{L}^{-}$cells (Fig. $2 E, F$ ). Thus, L1 expression by neural precursor cells increases neuronal differentiation and decreases proliferation.

$\mathrm{L1}^{+}$grafted cells show increased neuronal differentiation in the quinolinic acid-lesioned mouse striatum but do not influence endogenous neurogenesis

The differentiation potential of $\mathrm{L}^{+}{ }^{+}$and $\mathrm{L1}^{-}$cells was compared after transplantation into a mouse model with an acute and selective loss of GABAergic projection neurons. Stereotaxic injection of the NMDA receptor agonist quinolinic acid into the right striatum resulted in an almost complete depletion of neurons at the lesion site $3 \mathrm{~d}$ after injection (supplemental Fig. 1, available at www.jneurosci.org as supplemental material). ES cells differentiated to day 3 of stage 5 and injected into the center of the lesion $3 \mathrm{~d}$ after injection of quinolinic acid were identified by GFP expression 1-8 weeks afterward (see Fig. 6A-C). One week after transplantation, the number of neurons was significantly higher $(p<0.001)$ in $\mathrm{L}^{+}$grafts $(\beta$-tubulinIII, $22 \pm 3.2 \%)$ versus $\mathrm{L1}^{-}$ grafts $(\beta$-tubulinIII, $10 \pm 1.4 \%)$. Four and 8 weeks after transplantation, $\mathrm{L}^{+}$grafts showed a twofold increase in neurons [ $\beta$-tubulinIII, $47 \pm 2.5 \%$; NF, $44 \pm 4.3 \%$ ( 4 weeks); NF, $49 \pm$ $7.4 \%$ ( 8 weeks)] versus $\mathrm{L}^{-}{ }^{-}$grafts [ $\beta$-tubulinIII, $23 \pm 5.1 \%$; NF, $25 \pm 3.8 \%$ ( 4 weeks); NF, $30 \pm 8.7 \%$ ( 8 weeks)] and a corresponding decreased differentiation into GFAP ${ }^{+}$astrocytes $\left[\mathrm{L}^{+}{ }^{+}\right.$: $39 \pm 8.3 \%$ ( 4 weeks), $38 \pm 6.5 \%$ ( 8 weeks); $\mathrm{L1}^{-}: 54 \pm 6.1 \%$ (4 weeks), $63 \pm 6.8 \%$ ( 8 weeks) (Fig. 3 ). $\mathrm{MBP}^{+}$oligodendrocytes were hardly detectable in both groups $(<1 \%)$ (Fig. $3 B)$. To verify whether L1 exerts its beneficial functions by influencing proliferation or apoptosis in vivo, immunolabeling for the proliferation and apoptosis markers $\mathrm{Ki}-67$ and caspase-3, respectively, was performed 1 and 4 weeks after transplantation. The percentage of 
A

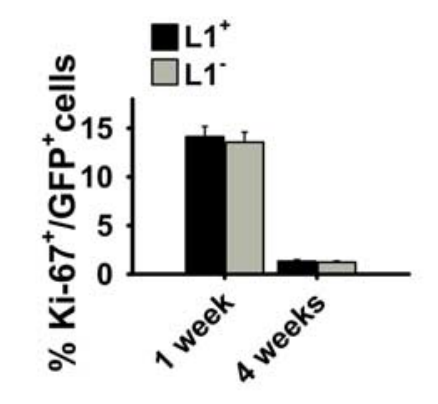

C

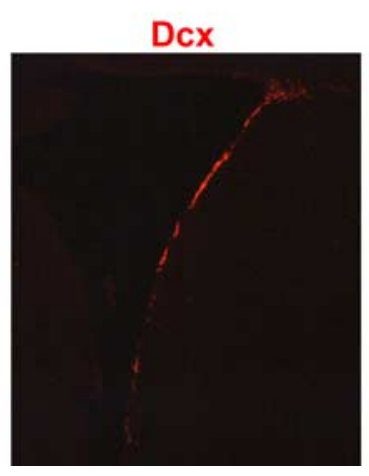

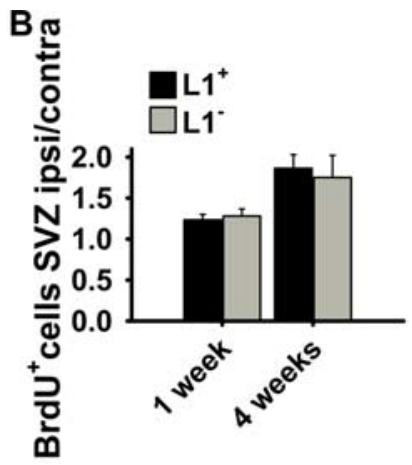

D

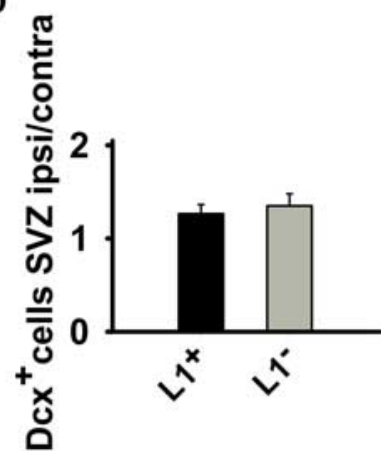

Figure 4. Analysis of proliferation in grafted cells by Ki-67 immunolabeling and of neurogenesis in the SVZ by BrdU incorporation and expression of DCX 1 and 4 weeks after transplantation. $\boldsymbol{A}$, The fraction of $\mathrm{Ki}-67^{+}$cells of all GFP ${ }^{+}$transplanted cells is given 1 and 4 weeks after transplantation of $\mathrm{L}^{+}(n=4)$ and $\mathrm{L1}^{-}(n=4)$ cells. No difference was observed. $\boldsymbol{B}$, Mice transplanted with $\mathrm{L1}^{+}(n=4)$ or $\mathrm{L1}^{-}(n=4)$ cells into the lesioned striatum were labeled with BrdU on days 3-7 after transplantation and killed $7 \mathrm{~d}$ and 4 weeks after grafting. The ratio of BrdU ${ }^{+}$cells in the SVZipsilateral and contralateral to the lesioned hemisphere is shown 1 and 4 weeks after transplantation. No difference was observed between the $\mathrm{L}^{+}{ }^{+}$and $\mathrm{L}^{-}{ }^{-}$groups. C, Immunohistochemical staining for DCX (red) in the SVZ ipsilateral to the lesion in shaminjected animals 4 weeks after grafting. D, Immunostaining for DCX in the SVZ was assessed 4 weeks after grafting. The ratio of DCX ${ }^{+}$cells in the SVZ ipsilateral and contralateral to the lesioned and transplanted hemisphere is given for mice transplanted with $\mathrm{L}^{+}(n=4)$ or $\mathrm{L}^{+}$ $(n=4)$ cells into the lesioned striatum. No difference between $\mathrm{L}^{+}$and $\mathrm{L}^{-}$groups was observed. Error bars indicate SEM. ipsi, Ipsilateral; contra, contralateral.

proliferating cells in the graft as assessed by Ki-67 immunolabeling was equal in both groups 1 and 4 weeks after transplantation (Fig. 4A). Furthermore, analysis of caspase-3 immunolabeling showed no significant difference in the percentage of caspase-3positive cells in $\mathrm{L}^{+}$and $\mathrm{L1}^{-}$grafts $\left[\mathrm{Ll}^{+}: 4.3 \pm 0.6 \%\right.$ (1 week), $<1 \%$ ( 4 and 8 weeks); $\mathrm{L1}^{-}: 5.1 \pm 0.7 \%$ ( 1 week), $<1 \%$ (4 and 8 weeks)]. Thus, L1 does not exert its beneficial effects in vivo by influencing proliferation or apoptosis in the grafts. In addition, levels of mRNA of neurotrophic factors BDNF, GDNF, NGF, and NT-3 were measured applying quantitative real-time PCR. No difference was detected in $\mathrm{Ll}^{+}$versus $\mathrm{L1}^{-}$grafts for all neurotrophic factors (supplemental Fig. 2, available at www.jneurosci.org as supplemental material). To investigate whether $\mathrm{L} 1^{+}$grafts influence neurogenesis within the subventricular zone (SVZ), we analyzed proliferation in the SVZ by BrdU pulse-labeling and measured the amount of $\mathrm{DCX}^{+}$-immunolabeled neurons within the SVZ in mice that had received $\mathrm{L}^{+}{ }^{+}$or $\mathrm{L}^{-}{ }^{-}$grafts. No differences were detected among the groups in the percentage of BrdUlabeled and $\mathrm{DCX}^{+}$neurons, indicating that $\mathrm{L} 1$ overexpression by the grafted cells does not influence endogenous neurogenesis (Fig. $4 B-D$ ). Thus, $\mathrm{L}^{+}$grafted cells show increased neuronal and decreased astrocytic differentiation in the quinolinic acidlesioned mouse striatum without influencing endogenous neurogenesis in the SVZ.

L1 expression in grafted cells leads to an increased number of graft-derived GABAergic neurons

In view of the selective loss of GABAergic neurons in the quinolinic acid lesion model and the increase in GABAergic differentiation of $\mathrm{L1}^{+}$cells in vitro, we next determined GABAergic differentiation in vivo. Differentiation of grafted cells into medium spiny GABAergic neurons was assessed by immunostaining for GAD (Fig. 5A) and DARPP (supplemental Fig. 3, available at www.jneurosci.org as supplemental material). As in vitro, an increased proportion of grafted $\mathrm{L}^{+}$cells differentiated into GABAergic neurons $1-8$ weeks after transplantation $[6 \pm 1.4 \%$ ( 1 week); $24 \pm 3.2 \%$ (8 weeks)] versus $\mathrm{L1}^{-}$cells $[3 \pm 0.2 \%(1$ week); $10 \pm 3.2 \%$ ( 8 weeks)] (Fig. $5 A, B$ ). This 2.5 -fold increase was not attributable to L1-specific induction of GABAergic differentiation, but rather reflected an increased overall neuronal differentiation, because the percentage of graft-derived $\mathrm{GAD}^{+}$of graft-derived $\mathrm{NF}^{+}$cells did not significantly differ between the two groups $\left(\mathrm{L}^{+}{ }^{+}, 46 \pm 9.8 \% ; \mathrm{L1}^{-}, 44 \pm 11.6 \% ; 8\right.$ weeks after grafting). However, because of the overall higher number of neurons in $\mathrm{L}^{+}$versus $\mathrm{L}^{-}$cells, the number of graft-derived GABAergic neurons was increased significantly in $\mathrm{L}^{+}{ }^{+}$versus $\mathrm{L} 1^{-}$grafts 1-8 weeks after transplantation (Fig. 5C). In $\mathrm{L}^{+}$ grafts $13,600 \pm 3300 \mathrm{GAD}^{+}$cells were detectable 1 week after transplantation compared with $6200 \pm 800 \mathrm{GAD}^{+}$cells in $\mathrm{L}^{-}$ grafts. The number of GAD ${ }^{+}$cells increased to 52,000 \pm 7200 in $\mathrm{L}^{+}$grafts versus $27,000 \pm 3600$ in $\mathrm{L}^{-}$grafts 4 weeks after transplantation. Eight weeks after grafting, the absolute numbers of $\mathrm{GAD}^{+}$cells had dropped in the $\mathrm{L1}^{+}$and $\mathrm{L1}^{-}$groups to $34,000 \pm 10,400$ and $18,000 \pm 6700$, respectively. This decrease in absolute numbers of GABAergic cells is explained by a decrease in total cell number, both for the $\mathrm{L}^{+}{ }^{+}$and $\mathrm{L}^{-}{ }^{-}$cells, 8 weeks after grafting (Fig. 5D). Interestingly, the numbers of graft-derived $\mathrm{TH}^{+}$dopaminergic neurons were negligible in both groups $\left(<1 \%\right.$ of all $\mathrm{GFP}^{+}$cells). Thus, L1 expression in grafted cells leads to an increased number of graft-derived GABAergic neurons in vivo.

\section{$\mathrm{L1}^{+}$cells migrate better than $\mathrm{L1}^{-}$cells}

Migration into the host tissue of $\mathrm{L}^{+}{ }^{+}$versus $\mathrm{L}^{-}{ }^{-}$cells differentiated to day 3 of stage 5 from the graft edge into the lesioned striatum was increased 4 weeks after grafting (Fig. 6A-D). Transplanted $\mathrm{L} 1^{-}$cells had migrated not more than $42 \pm 17 \mu \mathrm{m}$ away from the graft edge, whereas $\mathrm{L}^{+}$cells had migrated $110 \pm 42$ $\mu \mathrm{m}$, with individual $\mathrm{GAD}^{+}$cells showing considerable migration compared with the graft size (Fig. $6 A, B$ ).

\section{$\mathrm{L1}^{+}$cells improve locomotory recovery}

We tested the motor behavior of unilaterally quinolinic acidlesioned mice grafted either with $\mathrm{L}^{+}{ }^{+}$or $\mathrm{L}^{-}{ }^{-}$cells differentiated to day 3 of stage 5 or sham-injected with HBSS - . Stimulation with amphetamine induces a movement bias ipsilateral to the lesion site in quinolinic acid-injected mice. Sham-operated mice showed an abnormal and stable rotational bias (Fig. 6E). Mice grafted with $\mathrm{L1}^{-}$cells were not different from sham-injected mice and showed no recovery in rotational bias. In contrast, mice grafted with $\mathrm{L}^{+}{ }^{+}$cells showed a marked decrease in ipsilateral rotational deviation 1 and 4 weeks after transplantation, indicating that the $\mathrm{L}^{+}$graft can correct the behavioral abnormalities. Eight weeks after transplantation, rotational behavior did not differ significantly between the $\mathrm{L}^{+}$cell and sham-injected groups. 


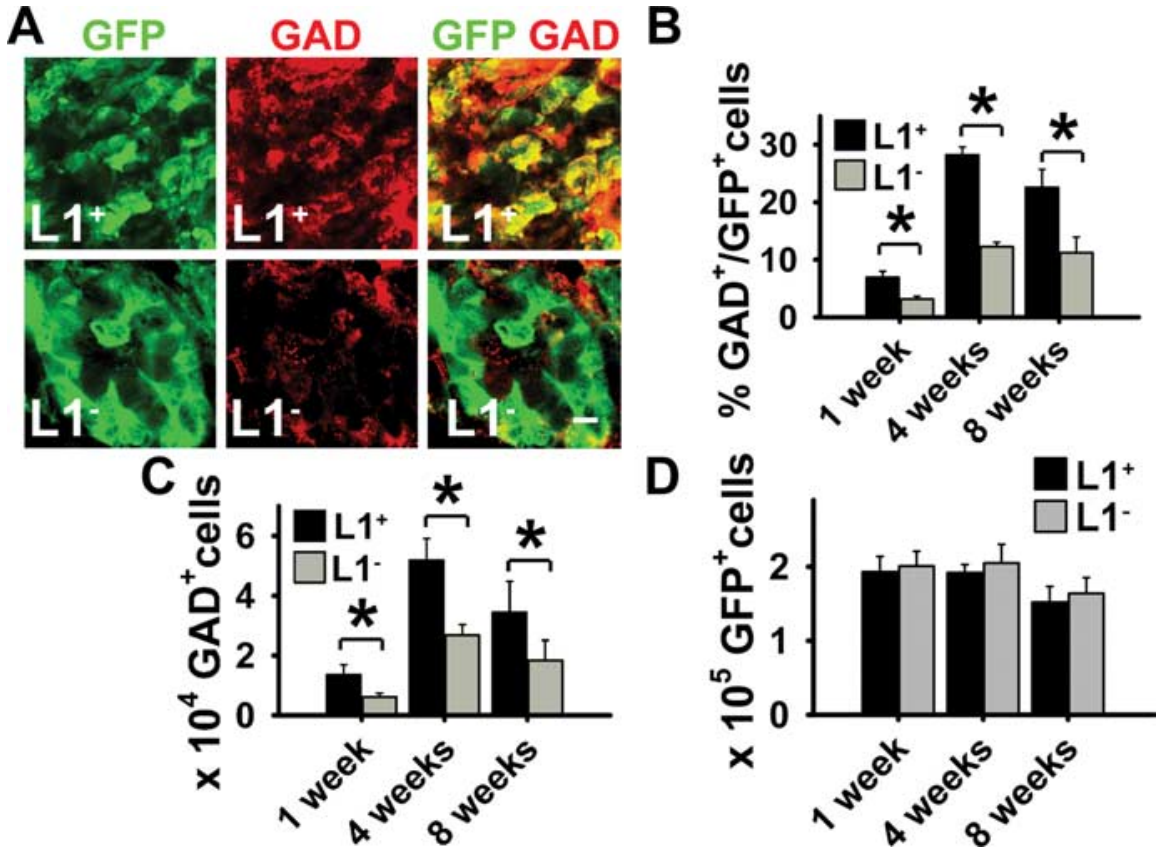

Figure 5. The number of GABAergic neurons is increased in $\mathrm{L}^{+}{ }^{+}$grafts. $\boldsymbol{A}$, Laser-scanning microscopy illustrating immunohistochemical analysis of grafts of early stage 5 cells derived from $\mathrm{L1}^{-}$and $\mathrm{L} 1^{+} \mathrm{ES}$ cells with the neuronal markers GAD (red) 8 weeks after transplantation of GFP ${ }^{+}$(green) cells. Donor-derived marker ${ }^{+}$cells in merged images appear yellow. Scale bar, 10 $\mu \mathrm{m} . \boldsymbol{B}$, Percentages of $\mathrm{GAD}^{+}$cells of GFP ${ }^{+}$cells in $\mathrm{L}^{+}(n=16)$ or $\mathrm{L1}^{-}(n=16)$ grafts $1-8$ weeks after transplantation. ANOVA followed by Student's $t$ test was performed for statistical analysis $\left({ }^{*} p<0.05\right)$. $C$, Total number of GAD ${ }^{+}$cells per graft $1-8$ weeks after transplantation. ANOVA followed by Student's $t$ test was performed for statistical analysis $\left({ }^{*} p<0.05\right)$. Note the increased number of GAD ${ }^{+}$cells in $\mathrm{L}^{+}{ }^{+}$grafts 1-8 weeks after transplantation compared with $\mathrm{L}^{-}{ }^{-}$grafts and the number of $\mathrm{GAD}^{+}$cells in both groups decreasing 8 weeks after transplantation and reflecting a decrease in total cell number. $\boldsymbol{D}$, Total numbers of graft-derived GFP ${ }^{+}$cells per graft 1- 8 weeks after transplantation. Error bars indicate mean \pm SEM

\section{Discussion}

We have shown in this study that the recognition molecule L1 influences beneficially the differentiation of ES cells into neurons at the expense of astrocytes and neural precursor cells both in vitro and in vivo. The larger proportion of $\mathrm{L1}^{+}$versus $\mathrm{L1}^{-}$cells differentiating into neurons in the lesioned striatum resulted in an overall increase in the absolute number of GABAergic neurons. $\mathrm{L}^{+}$cells showed decreased proliferation in vitro, indicating that the larger proportion of neurons in $\mathrm{L}^{+}{ }^{+}$cells is not attributable to increased proliferation of neuronally committed cells. This finding agrees with our previous results in which we showed that substrate-coated L1 decreased proliferation, increased neuronal differentiation, and decreased astrocytic differentiation of neural stem cells in vitro by selectively enhancing neuronal differentiation of multipotential neural precursors and bipotential neuron-astrocyte precursors (Dihné et al., 2003). In vivo, no difference in proliferation and cell death of grafted cells was detected in $\mathrm{L}^{+}{ }^{+}$versus $\mathrm{L}^{-}$grafts. Furthermore, no differences in the expression levels of several neurotrophic factors were detected. Thus, L1 does not exert its beneficial effects by influencing proliferation, cell death, or the expression of neurotrophic factors. Also, the number of DCX-immunoreactive cells in the SVZ was not different in mice with $\mathrm{L}^{+}{ }^{+}$grafts compared with mice with $\mathrm{L} 1^{-}$grafts, indicating that $\mathrm{L}^{+}{ }^{+}$grafts do not preferentially affect endogenous neurogenesis over $\mathrm{L}^{-}{ }^{-}$grafts.

Although 1 and 4 weeks after transplantation mice that had received $\mathrm{L}^{+}$cells showed an improved rotation behavior compared with mice that had received $\mathrm{L1}^{-}$grafts or sham-injected quinolinic acid-lesioned mice, 8 weeks after transplantation no significant differences were detected between the groups in that the rotation behavior of mice that received $\mathrm{L}^{+}$grafts deteriorated to a level comparable to mice that received $\mathrm{L1}^{-}$grafts or sham-injected mice. We interpret this observation as an indication that the number of $\mathrm{L}^{+}$cells at 1 and 4 weeks after transplantation is sufficient to improve functional recovery, whereas the decreased number of $\mathrm{L}^{+}{ }^{+}$cells 8 weeks after transplantation may not be sufficient. The reason why grafts shrink in size 8 weeks compared with 4 weeks after transplantation is presently not understood but may indicate the necessity to coexpress one or several neurotrophic factors together with L1 to provide long-term functional benefits.

The fact that lesion-induced motor imbalance is significantly better already 1 week after transplantation of $\mathrm{L}{ }^{+}$but not $\mathrm{L1}^{-}$cells points to the possibility that $\mathrm{L} 1$ either exerts its beneficial effects at early stages of migration and functional integration of grafted cells in the lesioned host tissue or that $\mathrm{L}^{+}{ }^{+}$cells improve the regenerative capacity of the host. The first possibility is supported by the fact that $\mathrm{L}^{+}$ cells migrate longer distances and differentiate twice as much into neurons compared with $\mathrm{L1}^{-}$cells. Thus, more neurons distribute more profusely within the host striatum, possibly causing rapid integration and functional recovery. The second possibility is mainly supported by the fact that already 1 week after transplantation the behavior of mice that received $\mathrm{L}^{+}$grafts is improved, suggesting that secondary neurodegenerative processes after the acute quinolinic acid lesion are beneficially influenced by L1, because within 1 week after transplantation, only a minor fraction of transplanted cells had differentiated into GABAergic neurons. As afferents from the cerebral cortex do not degenerate within 1 week after quinolinic acid injection into the striatum (Gianfriddo et al., 2003), it is also conceivable that corticostriatal afferents are spared more extensively from dying back in the presence of $\mathrm{L}^{+}{ }^{+}$cells than in the presence of $\mathrm{L}^{-}{ }^{-}$cells. It is not unlikely that these mechanisms of rescue and reconstitution by the grafted cells may operate simultaneously, thus leading to a concerted action of functional recovery.

Previous studies have shown that genetically modified neural stem cell lines producing NGF (Kordower et al., 1997) or BDNF (Martinez-Serrano and Bjorklund, 1996) were able to protect striatal neurons against excitotoxic damage after transplantation into the striatum, when injected 1 week before injection of quinolinic acid, thus demonstrating rescue of host cells and less deterioration in behavioral function. Rescue of degenerating GABAergic host cells by ciliary neurotrophic factor secreted by neural progenitor cells in the rat quinolinic acid model of Huntington's disease showed a significant decline in apomorphin-induced rotations compared with nontransfected cells (Weinelt et al., 2003). Proactive transplantation of human neural stem cells has also been shown to prevent degeneration of striatal neurons in a rat model of Huntington's disease when injected 1 week before injection of the toxic agent (Ryu et al., 2004). One recent study reports on stable induction of a GABAergic phenotype in a line of 
immortalized striatal neural stem cells through a special culture protocol demonstrating long-term survival and synaptic integration of graft neurons, but data on functional host recovery are lacking in this report (Bosch et al., 2004).

We used for the first time ES cellderived neural precursor cells in a syngeneic transplantation paradigm in mice to ameliorate the striatal tissue loss after lesioning. ES cells have so far never been shown to lead to functional recovery in the excitotoxic lesioning model of the striatum, and their differentiation in this experimental model system has not been studied before in vivo. The present study adds a novel aspect to the use of stem cells, and in particular ES cells, by engineering them to overexpress L1 as a potent neuronal survival as well as migration- and neurite outgrowth-promoting molecule. Because in our quinolinic acid model of excitotoxic lesion we could show that the striatal GABAergic projection neurons are depleted within $3 \mathrm{~d}$ after injection, the beneficial effects of transplanted stem cells must derive from their ability to substitute for the degenerated cells or from their ability to attenuate neurodegenerative processes, such as the secondary and delayed degeneration of corticostriatal projection neurons. Thus, our observations encourage the use of adhesion moleculeoverexpressing stem cells to promote migration and integration into the lesioned host tissue and rescue degenerating neurons and repopulate and reconnect neuron-depleted brain regions in an effort to therapeutically ameliorate neurodegeneration, possibly not only in Huntington's disease but also in other neurodegenerative diseases, by overcoming the present disadvantage that sustained long-term functional recovery was not achieved under our experimental conditions, indicating the necessity to improve graft survival by additional measures.

\section{References}

Appel F, Holm J, Conscience JF, Schachner M (1993) Several extracellular domains of the neural cell adhesion molecule L1 are involved in neurite outgrowth and cell body adhesion. J Neurosci 13:4764-4775.

Barbin G, Aigrot MS, Charles P, Foucher A, Grumet M, Schachner M, Zalc B, Lubetzki C (2004) Axonal cell-adhesion molecule L1 in CNS myelination. Neuron Glia Biol 1:65-72.

Bosch M, Pineda JR, Sunol C, Petriz J, Cattaneo E, Alberch J, Canals JM (2004) Induction of GABAergic phenotype in a neural stem cell line for transplantation in an excitotoxic model of Huntington's disease. Exp Neurol 190:42-58.

Chen J, Bernreuther C, Dihné M, Schachner M (2005) Cell adhesion molecule L1-transfected embryonic stem cells with enhanced survival support regrowth of corticospinal tract axons in mice after spinal cord injury. J Neurotrauma 22:896-906.

Chen S, Mantei N, Dong L, Schachner M (1999) Prevention of neuronal cell
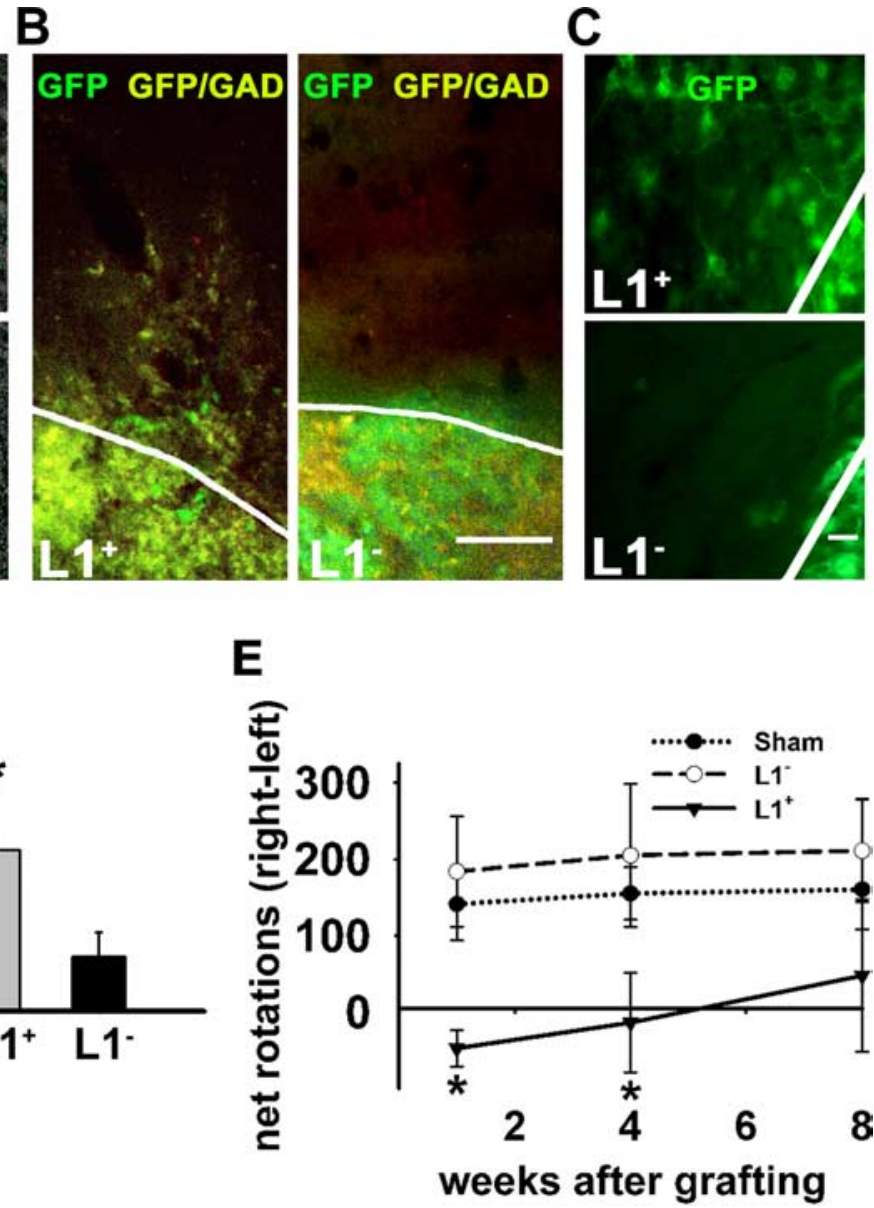

Figure 6. $\mathrm{L} 1^{+}$cells migrate better than $\mathrm{L}^{-}{ }^{-}$cells and improve locomotory recovery after quinolinic acid lesioning. $\boldsymbol{A}$, Phoright-field image of the host brain. Lateral ventricles are delineated by white lines. Note the increased amount of migrated cells , $B$, Images from the periphery of GFP ${ }^{+}$transplants stained with GAD antibody (GFP ${ }^{+} \mathrm{GAD}^{+}$cells appear yellow) of + transplants 4 weeks after grafting. White lines indicate graft edges. D. Average migration distance of 列 with unilateral quinolinic acid-induced striatal lesion grafted with cells differentiated to day 3 of stage 5 derived from L1 ${ }^{-}(n=$ calculated as number of right rotations minus the number of left rotations. ANOVA followed by the Newman-Keuls test was performed for statistical analysis (mean \pm SEM; ${ }^{*} p<0.05$ ). Scale bars: $\boldsymbol{A}, 100 \mu \mathrm{m} ; \boldsymbol{B}, 50 \mu \mathrm{m} ; \boldsymbol{C}, 20 \mu \mathrm{m}$.

death by neural adhesion molecules L1 and CHL1. J Neurobiol 38:428-439.

Demyanenko GP, Tsai AY, Maness PF (1999) Abnormalities in neuronal process extension, hippocampal development, and the ventricular system of L1 knock-out mice. J Neurosci 19:4907-4920.

Dihné M, Bernreuther C, Sibbe M, Paulus W, Schachner M (2003) A new role fort the cell adhesion molecule L1 in neural precursor cell proliferation, differentiation, and transmitter-specific subtype generation. J Neurosci 23:6638-6650.

Dong L, Chen S, Schachner M (2003) Single chain Fv antibodies against neural cell adhesion molecule L1 trigger L1 functions in cultured neurons. Mol Cell Neurosci 22:234-247.

Fransen E, Van Camp G, D’Hooge R, Vits L, Willems PJ (1998a) Genotypephenotype correlation in L1 associated diseases. J Med Genet 35:399-404.

Fransen E, D’Hooge R, Van Camp G, Verhoye M, Sijbers J, Reyniers E, Soriano P, Kamiguchi H, Willemsen R, Koekkoek SK, De Zeeuw CI, De Deyn PP, Van der Linden A, Lemmon V, Kooy RF, Willems PJ (1998b) L1 knockout mice show dilated ventricles, vermis hypoplasia and impaired exploration patterns. Hum Mol Genet 7:999-1009.

Fricker RA, Annett LE, Torres EM, Dunnett SB (1996) The placement of a 
striatal ibotenic acid lesion affects skilled forelimb use and the direction of drug-induced rotation. Brain Res Bull 41:409-416.

Gianfriddo M, Corsi C, Melani A, Pezzola A, Reggio R, Popoli P, Pedata F (2003) Adenosine $A_{2 A}$ antagonism increases striatal glutamate outflow in the quinolinic acid rat model of Huntington's disease. Brain Res 979:225-229.

Haney CA, Sahenk Z, Li C, Lemmon VP, Roder J, Trapp BD (1999) Heterophilic binding of L1 on unmyelinated sensory axons mediates Schwann cell adhesion and is required for axonal survival. J Cell Biol 146:1173-1184.

Howard CW, Reed MJ (1998) Unbiased stereology: three-dimensional measurement in microscopy. Oxford: Bios Scientific.

Kamiguchi H, Yoshihara F (2001) The role of endocytic L1 trafficking in polarized adhesion and migration of growth cones. J Neurosci 21:9194-9203.

Kleene R, Yang HB, Kutsche M, Schachner M (2001) The neural recognition molecule L1 is a sialic acid-binding lectin for CD24, which induces promotion and inhibition of neurite outgrowth. J Biol Chem 276:21656-21663.

Kordower JH, Chen EY, Winkler C, Fricker R, Charles V, Messing A, Mufson EJ, Wong SC, Rosenstein JM, Bjorklund A, Emerich DF, Hammang J, Carpenter MK (1997) Grafts of EGF-responsive neural stem cells derived from GFAP-hNGF transgenic mice: trophic and tropic effects in a rodent model of Huntington's disease. J Comp Neurol 13:96-113.

Law JW, Lee AY, Sun M, Nikonenko AG, Chung SK, Dityatev A, Schachner M, Morellini F (2003) Decreased anxiety, altered place learning, and increased CA1 basal excitatory synaptic transmission in mice with conditional ablation of the neural cell adhesion molecule L1. J Neurosci 23:10419-10432.

Lee SH, Lumelsky N, Studer L, Auerbach JM, McKay RD (2000) Efficient generation of midbrain and hindbrain neurons from mouse embryonic stem cells. Nat Biotechnol 18:675-679.

Lemmon V, Farr KL, Lagenaur C (1989) L1-mediated axon outgrowth occurs via a homophilic binding mechanism. Neuron 2:1597-1603.

Lindner J, Rathjen FG, Schachner M (1983) L1 mono- and polyclonal antibodies modify cell migration in early postnatal mouse cerebellum. Nature 305:427-430.

Luthi A, Mohajeri H, Schachner M, Laurent JP (1996) Reduction of hippocampal long-term potentiation in transgenic mice ectopically expressing the neural cell adhesion molecule L1 in astrocytes. J Neurosci Res 46:1-6.

Martinez-Serrano A, Bjorklund A (1996) Protection of the neostriatum against excitotoxic damage by neurotrophin-producing, genetically modified neural stem cells. J Neurosci 16:4604-4616.

Moos M, Tacke R, Scherer H, Teplow D, Fruh K, Schachner M (1988) Neural cell adhesion molecule $\mathrm{L} 1$ as a member of the immunoglobulin superfamily with binding domains similar to fibronectin. Nature 334:701-703.

Okabe S, Forsberg-Nilsson K, Spiro AC, Segal M, McKay RD (1996) Development of neuronal precursor cells and functional postmitotic neurons from embryonic stem cells in vitro. Mech Dev 59:89-102.

Pradel G, Schmidt R, Schachner M (2000) Involvement of L1.1 in memory consolidation after active avoidance conditioning in zebrafish. J Neurobiol 43:389-403.

Rathjen FG, Schachner M (1984) Immunocytological and biochemical characterization of a new neuronal cell surface component (L1 antigen) which is involved in cell adhesion. EMBO J 3:1-10.

Roonprapunt C, Huang W, Grill R, Friedlander D, Grumet M, Chen S, Schachner M, Young W (2003) Soluble cell adhesion molecule L1-Fc promotes locomotor recovery in rats after spinal cord injury. J Neurotrauma 20:871-882.

Ryu JK, Kim J, Cho SJ, Hatori K, Nagai A, Choi HB, Lee MC, McLarnon JG, Kim SU (2004) Proactive transplantation of human neural stem cells prevents degeneration of striatal neurons in a rat model of Huntington's disease. Neurobiol Dis 16:68-77.

Saghatelyan AK, Nikonenko AG, Sun M, Rolf B, Putthoff P, Kutsche M, Bartsch U, Dityatev A, Schachner M (2004) Reduced GABAergic transmission and number of hippocampal perisomatic inhibitory synapses in juvenile mice deficient in the neural cell adhesion molecule L1. Mol Cell Neurosci 26:191-203.

Seilheimer B, Persohn E, Schachner M (1989) Neural cell adhesion molecule expression is regulated by Schwann cell-neuron interactions in culture. J Cell Biol 108:1909-1915.

Tiunova A, Anokhin KV, Schachner M, Rose SP (1998) Three time windows for amnestic effect of antibodies to cell adhesion molecule L1 in chicks. NeuroReport 9:1645-1648.

Venero C, Tilling T, Hermans-Borgmeyer I, Herrero AI, Schachner M, Sandi C (2004) Water maze learning and forebrain mRNA expression of the neural cell adhesion molecule L1. J Neurosci Res 75:172-181.

Weinelt, S, Peters S, Bauer P, Mix E, Haas SJ, Dittmann A, Petrov S, Wree A, Cattaneo E, Knoblich R, Strauss U, Rolfs A (2003) Ciliary neurotrophic factor overexpression in neural progenitor cells (ST14A) increases proliferation, metabolic activity, and resistance to stress during differentiation. J Neurosci Res 71:228-236.

Wolfer DP, Mohajeri HM, Lipp HP, Schachner M (1998) Increased flexibility and selectivity in spatial learning of transgenic mice ectopically expressing the neural cell adhesion molecule L1 in astrocytes. Eur J Neurosci 10:708-717.

Wood P, Moya F, Eldridge C, Owens G, Ranscht B, Schachner M, Bunge M, Bunge R (1990) Studies of the initiation of myelination by Schwann cells. Ann NY Acad Sci 605:1-14.

Xu G, Nie DY, Wang WZ, Zhang PH, Shen J, Ang BT, Liu GH, Luo XG, Chen NL, Xiao ZC (2004) Optic nerve regeneration in polyglycolic acidchitosan conduits coated with recombinant L1-Fc. NeuroReport 15:2167-2172.

Zhang Y, Bo X, Schoepfer R, Holtmaat AJ, Verhaagen J, Emson PC, Lieberman AR, Anderson PN (2005) Growth-associated protein GAP-43 and L1 act synergistically to promote regenerative growth of Purkinje cell axons in vivo. Proc Natl Acad Sci USA 102:14883-14888. 